\title{
Prevalence of impacted premolars in a Turkish population and considerations for surgical treatment
}

\author{
Göksel Şimşek-Kaya ${ }^{1}$, Mehmet Melih-Ömezli ${ }^{2}$, Günay Yapıcı ${ }^{2}$, Ertunç Dayı ${ }^{3}$, Ümit Ertaş ${ }^{4}$ \\ ${ }^{1}$ Assistant Professor, Department of Oral and Maxillofacial Surgery, Faculty of Dentistry, Atatürk University \\ ${ }^{2}$ Research Assistant, Department of Oral and Maxillofacial Surgery, Faculty of Dentistry, Atatürk University \\ ${ }^{3}$ Professor, Department of Oral and Maxillofacial Surgery, Faculty of Dentistry, Atatürk University \\ ${ }^{4}$ Associate Professor, Department of Oral and Maxillofacial Surgery, Faculty of Dentistry, Atatürk University
}

\author{
Correspondence: \\ Atatürk University, \\ 25240, Erzurum (Turkey) \\ gokselsimsek@yahoo.com
}

Received: $31 / 03 / 2010$

Accepted: $31 / 05 / 2010$
Şimşek-Kaya G, Melih-Ömezli M, Yapici G, Dayi E, Ertaş U. Prevalence of impacted premolars in a Turkish population and considerations for surgical treatment. Med Oral Patol Oral Cir Bucal. 2011 Sep 1;16 (6):e781-6. http://www.medicinaoral.com/medoralfree01/v16i6/medoralv16i6p781.pdf

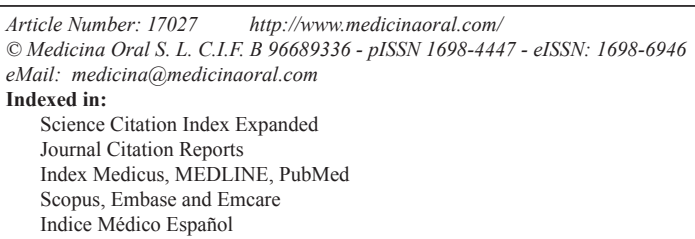

\begin{abstract}
Objective: The aim of this study was to identify the prevalence, associated pathology and symptoms, and treatment of impacted premolars in a Turkish population.

Study Design: This retrospective study examined panoramic radiographs and clinical records of 9,000 patients who presented consecutively at our oral and maxillofacial surgery clinics between January 1998 and January 2009. In addition to demographic data (patient sex and age), data was compiled on the number and location of impacted missing maxillary and mandibular premolars, retained deciduous molars, associated pathologies and symptoms, and treatment methods.

Results: A total of 105 impacted maxillary or mandibular premolars were observed in 93 patients (1.03\%). Of these, 48 (51.6\%) were female (age range: $13-57$ years) and 45 (43.4\%) were male (age range: 13-58 years). Impacted mandibular second premolars accounted for $55.2 \%(\mathrm{n}=58)$ of all impacted premolars. Migration was observed in only $11.83 \%$ of patients $(\mathrm{n}=11)$. Pathological changes and symptoms were noted in $15.05 \%$ of patients.

Conclusion: Our results suggest that the prophylactic extraction of non-migrated impacted premolars may not be necessary. If the patient is cooperative, a "wait and see" approach may be preferable. Orthodontic or prosthetic treatment options should also be considered when planning treatment of non-migrated impacted premolars. Migrated impacted premolars should be kept under observation and should only be removed if they are associated with pathology or if extraction is required for prosthetic or orthodontic treatment.
\end{abstract}

Key words: Impacted premolars, pathology, symptom, migration, treatment. 


\section{Introduction}

Teeth that fail to erupt or develop in the proper functional location may become impacted. Non-functional, abnormal, or pathological impacted permanent teeth have a prevalence of $5.6-28.3 \%$ and are considered a problem for all branches of dentistry (1-4). The most commonly impacted teeth are the third molars, maxillary canines, maxillary central incisors and premolars $(2,4-7)$. Impacted premolars may lead to aesthetic concerns, masticatory inefficiency and oral hygiene difficulties (4) as well as follicle pathology and destruction of adjacent structures, including neighboring teeth $(4,7)$.

The literature contains a limited number of case reports and comprehensive studies on impacted premolars; therefore, this study aimed to identify the prevalence, associated pathology and symptoms, and methods of treatment of impacted premolars in a Turkish population.

\section{Materials and Methods}

This retrospective study examined panoramic radiographs and clinical records of 9,000 patients over the age of 12 who presented consecutively at our oral and maxillofacial surgery clinics between January 1998 and January 2009. A tooth was considered to be impacted if it was not exposed to the oral cavity in a patient over 12 years of age. Panoramic radiographs were examined simultaneously by five oral and maxillofacial surgeons using standard light boxes. Data was collected on the number and localization of impacted maxillary and mandibular premolars and retained deciduous molars, as well as any associated pathologies or symptoms. Demographic information (patient sex and age) and treatment methods were also noted.

Impacted premolars were classified as to location based on whether or not they had undergone intra-osseous migration, which was defined as the movement of a tooth to an area far from its regular place of development $(3,8,9)$. Migrated premolars were classified according to the direction of migration and location of the migrated crown, whereas non-migrated impacted premolars were classified according to depth (10) and angulation (11) of impaction using modified criteria for third molar classification. Depth classification was as follows: Class1 (High occlusal level): the most superficial part of the premolar is located on a level with the occlusal plane; Class 2 (Medium occlusal level): the most superficial part of the premolar is located between the occlusal plane and the cement-enamel junction of the adjacent teeth; Class 3 (Deep occlusal level): the most superficial part of the premolar is located apically to the cementenamel junction of the adjacent teeth. Angulation was classified as follows: vertical (V): $0-10^{\circ}$; mesioangular (M) or distoangular (D): $11^{\circ}-70^{\circ}$; horizontal $(\mathrm{H}): \geq 71^{\circ}$; and a group of cases with inverted or buccolingual angulation were combined as inverted (I).

\section{Results}

A total of 105 impacted maxillary or mandibular premolars were observed in 93 patients $(1.03 \%)$. Of these, 48 (51.6\%) were female (mean age, 25.78 years; range, 13-57 years) and 45 (43.4\%) were male (mean age, 26.33 years; range, $13-58$ years). The male to female ratio for patients with impacted maxillary first and second premolars was $1: 4$ and 1:0.5, respectively, and the ratio for patients with impacted mandibular first and second premolars was 1:1 and 1:1.2, respectively. The vast majority of impacted teeth were unilateral. Bilateral impacted premolars were observed as follows: maxillary first premolars: 2 patients; maxillary second premolars: 2 patients; mandibular first premolars: 1 patient; mandibular second premolars: 7 patients. Mandibular second premolars accounted for $55.2 \%(\mathrm{n}=58)$ of all impacted premolars. Whereas impaction rates of mandibular second premolars were higher than those of maxillary second premolars, impaction rates for mandibular and maxillary first premolars were similar. Depth and angulation of impaction differed between maxillary and mandibular premolars (Table 1). In addition to impacted teeth, 10 deciduous first molars were retained in 6 patients (aged 13-19), and 16 permanent first molars were extracted from 16 patients (aged 19-57). Intra-osseously migrated mandibular second premolars were observed in 11 patients $(11.83 \%)$; of these, 7 were female (aged 22-57) and four were male (aged 21-41). All migrated premolars were unilateral, and all migration occurred distally, although the localization of migrated teeth varied. Mandibular permanent first molars were extracted from 4 patients with migrated premolars (Fig. 1), and mandibular permanent first, second and third molars were extracted from 5 patients with migrated premolars (Table 2).

Of the 105 impacted premolars identified, 5 (4.7\%; patient age: 13-44 years) were associated with odontomas. Of these, 4 were surgically removed, and the eruption of the impacted permanent teeth was monitored, whereas the fifth odontoma, which was embedded in a cystic lesion $(0.95 \%$; patient age: 19 years), was removed with the related premolar (Fig. 2). Another tooth with an infected cyst was also extracted together with the infected cyst. In total, 3 cystic lesions were observed, two of which were removed (1.9\%; patient age: 13 and 44 years), and one of which ( $0.95 \%$; patient age: 13 years) was marsupialized in order to permit eruption of the impacted tooth. One tooth ( $0.95 \%$; patient age: 45 years) was also extracted due to root resorption of the adjacent tooth, and 6 teeth not associated with either a tumor or a cyst were extracted because they were causing pain. Of these, 3 teeth (2.85\%; patient age: $28-37$ years) were infected, whereas 3 teeth (2.85\%; patient age: $21-57$ years) showed no signs of infection.

All other impacted teeth were asymptomatic. Of these, 13 (12.4\%; patient age: 13-22 years) were extracted for 
Table 1. Angular position, impaction depth for non-migrated impacted premolars (pm).

\begin{tabular}{|c|c|c|c|c|c|}
\hline & & $\begin{array}{c}\text { Maxillary } \\
\text { 1. pm } \\
\end{array}$ & $\begin{array}{c}\text { Maxillary } \\
\text { 2. pm } \\
\end{array}$ & $\begin{array}{c}\text { Mandibular } \\
\text { 1.pm }\end{array}$ & $\begin{array}{c}\text { Mandibular } \\
\text { 2. pm }\end{array}$ \\
\hline \multicolumn{2}{|c|}{ Cases } & $5(0.05 \%)$ & $20(0.22 \%)$ & $10(0.11 \%)$ & $58(0.64 \%)$ \\
\hline \multirow{3}{*}{ Depth } & Class-1 & $1(14.3 \%)$ & $4(18.2 \%)$ & $4(36.4 \%)$ & $17(26.2 \%)$ \\
\hline & Class- 2 & $6(85.7 \%)$ & $15(68.2 \%)$ & $5(45.4 \%)$ & $39(60 \%)$ \\
\hline & Class- 3 & 0 & $3(13.6 \%)$ & $2(18.2 \%)$ & $9(13.8 \%)$ \\
\hline \multirow{5}{*}{ Angulation } & Mesio- angular & $5(71.4 \%)$ & $11(50 \%)$ & $1(9.1 \%)$ & $21(32.3 \%)$ \\
\hline & Disto-angular & $2(28.6 \%)$ & $2(9.1 \%)$ & $2(18.2 \%)$ & $19(29.2 \%)$ \\
\hline & Vertical & 0 & $7(31.9 \%)$ & $6(54.5 \%)$ & $11(16.9 \%)$ \\
\hline & Horizontal & 0 & $1(4.5 \%)$ & $2(18.2 \%)$ & $14(21.5 \%)$ \\
\hline & Inverted & 0 & $1(4.5 \%)$ & 0 & 0 \\
\hline
\end{tabular}

Table 2. Clinical and radiographical features of migrated mandibular 2. pm observed in the present study.

\begin{tabular}{|c|c|c|c|c|c|c|c|c|c|c|c|}
\hline Pn & Age & Sex & Dm & 2. pm & $\begin{array}{l}\text { Position of the crown of } \\
\text { the migrated pm on the } \\
\text { radiogram }\end{array}$ & Es & $\begin{array}{c}\text { Uni/ } \\
\text { Bi }\end{array}$ & Rdm & $\begin{array}{l}\text { Extracted } \\
\text { of per } 1 . \mathrm{m}\end{array}$ & $\begin{array}{r}\text { Associated } \\
\text { pathology }\end{array}$ & $\begin{array}{l}\text { Treatment } \\
\text { protocol }\end{array}$ \\
\hline 1 & 22 & $\mathrm{~F}$ & $\mathrm{D}$ & $\mathrm{R}$ & $\begin{array}{l}\text { The mandibular } 2 \text {. } \\
\text { premolar is in contact with } \\
\text { the mesial root of the } \\
\text { mandibular third molar }\end{array}$ & I & $\mathrm{U}$ & $\mathrm{CE}$ & Yes & None & Observation \\
\hline 2 & 21 & M & $\mathrm{D}$ & $\mathrm{R}$ & At the molar region & I & $\mathrm{U}$ & $\mathrm{CE}$ & No & Pain & Extraction \\
\hline 3 & 57 & $\mathrm{~F}$ & $\mathrm{D}$ & $\mathrm{L}$ & $\begin{array}{l}\text { At the anterior site of the } \\
\text { mandibular ramus }\end{array}$ & I & $\mathrm{U}$ & $\mathrm{CE}$ & Yes & Pain & Extraction \\
\hline 4 & 36 & $\mathrm{~F}$ & $\mathrm{D}$ & $\mathrm{L}$ & $\begin{array}{l}\text { The mandibular } 2 \text {. } \\
\text { premolar is in contact with } \\
\text { the mesial root of the } \\
\text { mandibular second molar }\end{array}$ & I & $\mathrm{U}$ & $\mathrm{CE}$ & Yes & None & Observation \\
\hline 5 & 28 & M & $\mathrm{D}$ & $\mathrm{L}$ & $\begin{array}{l}\text { The mandibular } 2 \text {. } \\
\text { premolar is in contact with } \\
\text { the mesial root of the } \\
\text { mandibular second molar }\end{array}$ & I & $\mathrm{U}$ & $\mathrm{CE}$ & Yes & Abscess & Extraction \\
\hline 6 & 21 & $\mathrm{~F}$ & $\mathrm{D}$ & $\mathrm{L}$ & $\begin{array}{l}\text { Just below the mandibular } \\
\text { permanent third molar }\end{array}$ & $\mathrm{I}$ & $\mathrm{U}$ & $\mathrm{CE}$ & Yes & None & Extraction \\
\hline 7 & 29 & $\mathrm{~F}$ & $\mathrm{D}$ & $\mathrm{L}$ & $\begin{array}{l}\text { At the anterior site of the } \\
\text { mandibular ramus }\end{array}$ & I & U & $\mathrm{CE}$ & Yes & None & Observation \\
\hline 8 & 40 & M & $\mathrm{D}$ & $\mathrm{R}$ & $\begin{array}{l}\text { At the anterior site of the } \\
\text { mandibular ramus }\end{array}$ & I & $\mathrm{U}$ & $\mathrm{CE}$ & Yes & None & Observation \\
\hline 9 & 40 & $\mathrm{~F}$ & $\mathrm{D}$ & $\mathrm{R}$ & $\begin{array}{l}\text { At the anterior site of the } \\
\text { mandibular ramus }\end{array}$ & $\mathrm{I}$ & U & $\mathrm{CE}$ & Yes & None & $\begin{array}{l}\text { Prosthetic } \\
\text { Extraction }\end{array}$ \\
\hline 10 & 41 & M & $\mathrm{D}$ & $\mathrm{R}$ & $\begin{array}{l}\text { Just below the mandibular } \\
\text { permanent second molar }\end{array}$ & $\mathrm{I}$ & $\mathrm{U}$ & $\mathrm{CE}$ & No & Pain & Extraction \\
\hline 11 & 36 & $\mathrm{~F}$ & $\mathrm{D}$ & $\mathrm{R}$ & At the molar region & I & $\mathrm{U}$ & $\mathrm{CE}$ & Yes & None & $\begin{array}{l}\text { Prosthetic } \\
\text { Extraction }\end{array}$ \\
\hline
\end{tabular}

Pn; Patient no, F; Female, M; Male, Dm; Direction of migration, D; Distal, R; Right, L; Left, pm; premolar, Es; Eruption status, I; Impact, Uni/Bi; Unilateral/Bilateral, Rdm; Retained deciduous molar, CE; Exfoliated deciduous molar, Per; Permanent; m; molar. 
orthodontic reasons, 11 (10.5\%; patient age: $30-58$ years) for prosthetic reasons and $29(27.6 \%)$ at the request of the patient. Moreover, 10 retained deciduous molars (patient age: 14-21 years) were extracted to permit eruption of the permanent premolars (Fig. 3). In addition, 20 impacted teeth (19\%; patient age: 13-21 years) were treated using surgical exposure and orthodontic traction and 23 teeth (21.9\%; patient age: $13-40$ years) were followed-up without any intervention.

All treatment was performed under local anesthesia using an intraoral approach.

None of the patients with impacted premolars had a history of maxillofacial or dento-alveolar trauma, surgery, anomalies or syndromes.

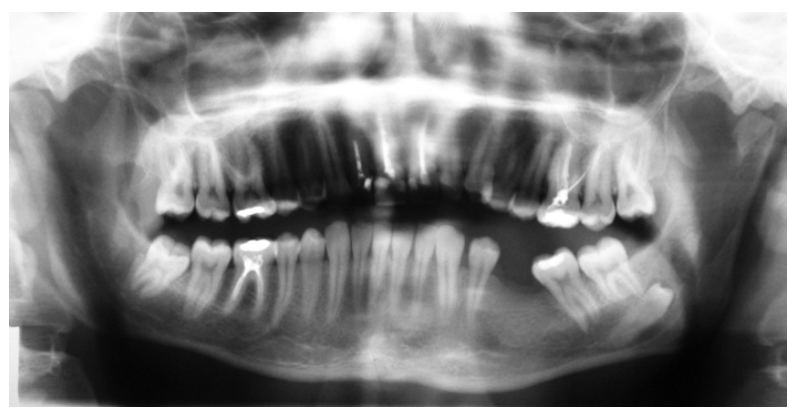

Fig. 1. An impacted left mandibular second premolar that has migrated below a permanent mandibular third molar.

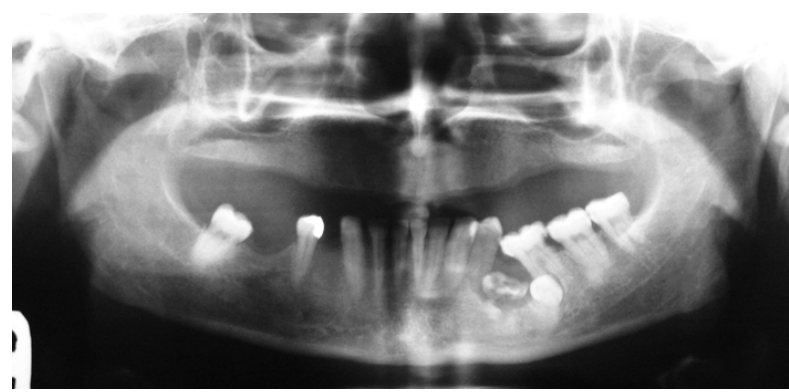

Fig. 2. An impacted left mandibular second premolar associated with an odontoma in a cystic lesion.

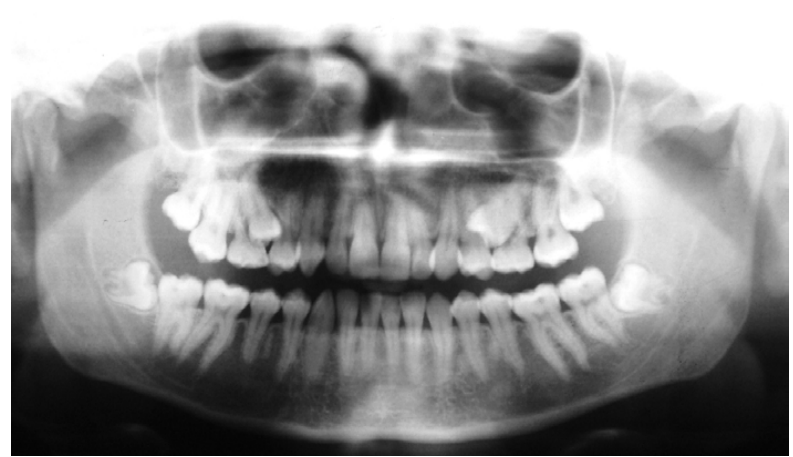

Fig. 3. Primary molars impeding the eruption of permanent maxillary premolars.

\section{Discussion}

Tooth impaction may be the result of local or general factors (12). The most common local factors include abnormal positioning of the permanent tooth bud; prolonged retention, ankylosis, or early exfoliation of the deciduous tooth; insufficient area for eruption of the permanent tooth; alveolar clefts; cysts; and odontomas $(2,4,6,7,13)$. Among this study population, impaction of premolars was associated with retained primary molars, odontomas, or cysts in $18.3 \%$ of all cases.

The prevalence of impacted premolars has been reported to range from $0.1 \%$ to $0.3 \%$ for maxillary premolars and from $0.2 \%$ to $0.3 \%$ for mandibular premolars $(4,14)$. In our population, the prevalence of impacted maxillary first and second premolars was $0.05 \%$ and $0.22 \%$, respectively, and the prevalence of impacted mandibular first and second premolars was $0.11 \%$ and $0.64 \%$, respectively. Differences in prevalence rates between this study and previous studies may be due to differences in the genetic backgrounds of the patients.

Intra-osseous migration is a very rare dental anomaly that occurs only in permanent dentition $(8,15,16)$. Migration of the mandibular second premolar has been reported to occur at a rate of $0.2 \%$ (17) and in subjects over 20 years of age (18). In our study, 11 teeth had undergone migration, all in patients over age 20 . In line with the literature $(8,15)$, in our study, only unilateral migration was observed. In 9 of the 11 cases of migration, the permanent mandibular first molar had previously been extracted.

The mechanism of distal migration is not completely understood, since the mandibular premolars present mesial movement due to masticatory efforts (19). Our findings suggest that the extraction of the permanent first molar may play an important role in the migration of impacted mandibular second premolars. Further studies are needed to clarify the exact mechanism of migration.

In cases where impacted premolars have sufficient space for eruption, treatment alternatives consist of periodic observation; extraction of the primary tooth and monitoring of the permanent tooth; surgical exposure and exteriorization, with or without orthodontic traction; surgical repositioning (autotransplantation); and surgical extraction of the impacted premolar $(2,4,5,7,13)$. In this study, 10 retained primary molars and 62 impacted premolars were extracted. Although eruption of an impacted tooth may occur spontaneously following surgical exposure, orthodontic alignment may be required in some cases $(4,6,7,13)$. In this study, 20 teeth were treated using a combination of surgical exposure and orthodontic traction. Some authors such as Kim et al. (20), Jain et al. (21) observed that probability of mandibular third molar eruption is related to premolars extraction. In contrast, Tarazona et al. (22) demonstrated that the 
angulation of third molar improves with time regardless of treatment, and presents a greater disinclusion in cases treated with extractions. In this study, none of the impacted premolars extracted to contribution of third molar eruption.

In general, when an impacted tooth is accompanied by a pericoronal lesion, both tooth and lesion are extracted to prevent recurrence of the cyst. However, it is also possible to marsupialize the cyst in order to preserve the impacted tooth and accelerate its eruption (5). Among our study population, 3 cysts were identified. Of these, one cyst that was observed in a young patient showed no signs of infection and was marsupialized, and the impacted tooth monitored. However, 2 other impacted premolars associated with cysts were extracted, in one case because the cyst was infected, and in the other case because the cyst was accompanied by an odontoma and the tooth malpositioned.

Extraction is also indicated for impacted premolars that have resulted in root resorption of the adjacent teeth, periodontal disturbances, or neurological symptoms (15). In this study, one tooth had caused resorption in the mesial root of the mandibular permanent first molar and was extracted, and 6 teeth unrelated to a cyst or tumor were extracted because they were causing pain. In 3 of these cases, the pain was due to infection, whereas in the other 3 cases, the pain was a result of the close proximity of the impacted tooth to the mandibular canal.

Treatment options for an ectopically impacted premolar include leaving the tooth in situ; prophylactic extraction using either an intraoral or extraoral approach, depending on the position of the tooth; surgical exposure and alignment of the tooth in the dental arch; and, in cases where a premolar has migrated to the space of an extracted adjacent permanent first molar, orthodontic traction $(9,15,16,23)$. Attempts to rescue deeply impacted and migrated premolars may result in damage to the roots of adjacent teeth (15). Moreover, in inaccessible areas such as the angle of the mandible, a limited surgical field and poor visualization make an intraoral approach difficult, whereas an extraoral approach poses the risk of injury to the facial nerve and the cosmetic sequela of an unaesthetic scar (16). In this study, 7 migrated premolars were extracted.

\section{Conclusions}

In conclusion, our data suggests that in the absence of specific medical and surgical pathology, prophylactic extraction of non-migrated premolars may not be necessary. If the patient is cooperative, has realistic expectations and a positive attitude towards treatment, and is available for regular follow-up, a "wait and see" policy can be adopted. For non-migrated impacted premolars, an orthodontic or prosthetic approach should be consid- ered when devising a treatment plan. Migrated impacted premolars should be kept under observation and should only be removed if they are associated with pathology or if extraction is required for prosthetic or orthodontic treatment.

\section{References}

References with links to Crossref-DOI

1. Obiechina AE, Arotiba JT, Fasola AO. Third molar impaction: evaluation of the symptoms and pattern of impaction of mandibular third molar teeth in Nigerians. Odontostomatol Trop. 2001;24:22-5.

2. Murray P, Brown NL. The conservative approach to managing unerupted lower premolars -- two case reports. Int J Paediatr Dent. 2003;13:198-203.

3. Shapira Y, Borell G, Kuftinec MM, Stom D, Nahlieli O. Bringing impacted mandibular second premolars into occlusion. J Am Dent Assoc. 1996;127:1075-8.

4. Lee PP. Impacted premolars. Dent Update. 2005;32:152-4,157.

5. Karapanou V. Endodontic management of an impacted premolar. J Clin Pediatr Dent. 2005;29:293-8.

6. Burch J, Ngan P, Hackman A. Diagnosis and treatment planning for unerupted premolars. Pediatr Dent. 1994;16:89-95.

7. McNamara C, McNamara TG. Mandibular premolar impaction: 2 case reports. J Can Dent Assoc. 2005;71:859-63.

8. Okada H, Miyake S, Toyama K, Yamamoto H. Intraosseous tooth migration of impacted mandibular premolar: computed tomography observation of 2 cases of migration into the mandibular neck and the coronoid process. J Oral Maxillofac Surg. 2002;60:686-9.

9. Loh HS. Migration of unerupted mandibular premolars. Br Dent J. 1988;164:324-5.

10. Nordenram A. [Positional relationships of the impacted $3 \mathrm{~d}$ molar (classification of 1179 cases in an oral-surgical remitted material]. Sven Tandlak Tidskr. 1966;59:591-600.

11. Shiller WR. Positional changes in mesio-angular impacted mandibular third molars during a year. J Am Dent Assoc. 1979;99:460-4.

12. Bishara SE. Impacted maxillary canines: a review. Am J Orthod Dentofacial Orthop. 1992;101:159-71.

13. Kobaiashi VT, Mitomi T, Taguchi Y, Noda T. Occlusal guidance for eruption disturbance of mandibular second premolar: a report of three cases. J Clin Pediatr Dent. 2003;27:101-5.

14. Chu FC, Li TK, Lui VK, Newsome PR, Chow RL, Cheung LK. Prevalence of impacted teeth and associated pathologies--a radiographic study of the Hong Kong Chinese population. Hong Kong Med J. 2003;9:158-63.

15. Shapira Y, Kuftinec MM. Intrabony migration of impacted teeth. Angle Orthod. 2003;73:738-43.

16. Infante-Cossio P, Hernandez-Guisado JM, Gutierrez-Perez JL. Removal of a premolar with extreme distal migration by sagittal osteotomy of the mandibular ramus: report of case. J Oral Maxillofac Surg. 2000;58:575-7.

17. Matteson SR, Kantor ML, Proffit WR. Extreme distal migration of the mandibular second bicuspid. A variant of eruption. Angle Orthod. 1982;52:11-8.

18. Sutton PR. Migrating nonerupted mandibular premolars: a case of migration into the coronoid process. Oral Surg Oral Med Oral Pathol. 1968;25:87-98.

19. Alves DB, Pedrosa EF, Andreo JC, de Carvalho IM, Rodrigues Ade C. Transmigration of mandibular second premolar in a patient with cleft lip and palate--case report. J Appl Oral Sci. 2008;16:360-3.

20. Kim TW, Artun J, Behbehani F, Artese F. Prevalence of third molar impaction in orthodontic patients treated nonextraction and with extraction of 4 premolars. Am J Orthod Dentofacial Orthop. 2003;123:138-45.

21. Jain S, Valiathan A. Influence of first premolar extraction on mandibular third molar angulation. Angle Orthod. 2009;79:1143-8. 22. Tarazona B, Paredes V, Llamas JM, Cibrian R, Gandía JL. Influence of first and second premolar extraction or non-extraction treat- 
ments on mandibular third molar angulation and position. A comparative study. Med Oral Patol Oral Cir Bucal. 2010;15:e760-6.

23. Peck S. On the phenomenon of intraosseous migration of nonerupting teeth. Am J Orthod Dentofacial Orthop. 1998;113:515-7.

*This study was presented at the 3rd. International Oral and Maxillofacial Surgery Society Congress, 37, Antalya, 2009. 